\title{
Seasonal Variations and Health Risk Assessment of Trace Elements in Seti River Basin, Gandaki Province, Nepal
}

\author{
Ramesh Raj Pant \\ Tribhuvan University \\ Jharana Nepal \\ Tribhuvan University \\ Sudip Paudel \\ Tribhuvan University \\ Mohan Bahadur Chand \\ Hokkaido University: Hokkaido Daigaku

\section{Faizan Ur Rehman Qaisar} \\ COMSATS University Islamabad \\ Khadka Bahadur Pal \\ Tribhuvan University \\ Lal B Thapa \\ Tribhuvan University \\ Guanxing Wang \\ Tribhuvan University
}

Kiran Bishwakarma ( $\nabla$ kiranghatani2019@itpcas.ac.cn )

Institute of Tibetan Plateau Research Chinese Academy of Sciences

\section{Research Article}

Keywords: Seasonal variations, trace elements, water quality index, health risk assessment, Himalayan River Basin

Posted Date: April 12th, 2021

DOl: https://doi.org/10.21203/rs.3.rs-392824/v1

License: (c) (1) This work is licensed under a Creative Commons Attribution 4.0 International License.

Read Full License 


\title{
Seasonal Variations and Health Risk Assessment of Trace Elements in Seti River Basin, Gandaki
}

\section{Province, Nepal}

Ramesh Raj Pant ${ }^{1}$, Kiran Bishwakarma ${ }^{2,3 *}$, Jharana Nepal ${ }^{1}$, Sudip Paudel ${ }^{1}$, Mohan Bahadur Chand ${ }^{4}$, Faizan Ur Rehman Qaisar ${ }^{5}$, Khadka Bahadur Pal ${ }^{6}$, Lal B Thapa ${ }^{7}$, and Guanxing Wang ${ }^{2}$

${ }^{1}$ Central Department of Environmental Science, Tribhuvan University, Nepal

${ }^{2}$ Key Laboratory of Tibetan Environment Changes and Land Surface Processes, Institute of Tibetan Plateau Research, Chinese Academy of Sciences, Beijing 100101, China

${ }^{3}$ University of Chinese Academy of Sciences, Beijing 100101, China

${ }^{4}$ Faculty of Environmental Earth Science, Hokkaido University, Sapporo, Hokkaido 060-0810, Japan.

${ }^{5}$ Department of Earth Sciences COMSATS University Islamabad, Abbottabad Campus, Pakistan

${ }^{6}$ Department of Chemistry, Tri-Chandra Multiple Campus, Tribhuvan University, Kathmandu, Nepal

${ }^{7}$ Central Department of Botany, Institute of Science and Technology, Tribhuvan University, Nepal

*Corresponding author: Bishwakarma Kiran, Email: kiranghatani2019@itpcas.ac.cn

\begin{abstract}
To explore the seasonal variability and associated health risks of dissolved trace elements (TEs), a total of 45 water samples (15 samples in each season) were collected from the Seti River Basin during premonsoon, monsoon, and post-monsoon seasons. A total of 15 (TEs) were analysed and the results revealed that Arsenic (As), Chromium (Cr), and Nickel (Ni) were primarily controlled by lithogenic sources, whereas, Cadmium (Cd), Cobalt (Co), Cesium (Cs), Cupper (Cu), Manganese (Mn), Lead $(\mathbf{P b})$, and Zinc ( $\mathbf{Z n})$ were derived from both anthropic and geogenic origin. Additionally, the concentration of $\mathrm{Zn}$ was markedly high, especially during the post-monsoon season nearby the landfill site, indicating the anthropic signatures. The hazard index and cancer index were found to be $<1.00$ and $10^{-6}-10^{-4}$, respectively indicating minimum health impacts. The water quality index was $<50$ throughout the sampling periods, with better water quality during the monsoon. This study could help to formulate the necessary policies for the sustainability of the Himalayan River Basins.
\end{abstract}

Keywords: Seasonal variations; trace elements; water quality index; health risk assessment; Himalayan River Basin

\section{Introduction}

The quality of freshwater bodies has been considerably attracting both public and scientific attention over the past few decades (Gaillardet et al., 2014; Pant et al., 2020). The contamination of the aquatic ecosystem and its implications for human and ecological health are great concerns worldwide (Li and Zhang, 2010, 2008). Owing to the toxicity, bio-accumulative, and biomagnifying characteristics of the trace elements (TEs) contamination, the public health issues are a matter of serious concern especially in developing countries (Meng et al., 2016; Rupakheti et al., 2017). The controlling mechanisms and the abundance of the TEs in the aquatic environment are largely determined by the complex interaction among the precipitation, surface/groundwater, including various environmental factors (Varol et al., 2013). The major sources of such contaminants in the water are both natural-geogenic and anthropic activities including municipal wastes, agricultural runoff, and industrial effluents (Li and Zhang, 2010; Pant et al., 2020). Additionally, global climate change and the long-range transport of pollutants also threaten the quality of the freshwater environments, especially in the Himalaya. 
Numerous researches have been conducted to assess the human and ecological health risks of TEs including their toxicity and carcinogenicity (Ustaoğlu and Tepe, 2019; Wang et al., 2017). The studies have reported that the intake of contaminated water with TEs cause several risks on human health, depending on the type, amount, and toxicity of the elements; for instance, the specific amount of certain TEs (e.g., Co, Cu, $\mathrm{Zn}$ ), are essentially required for normal body growth and functioning, however, their excessive amount may be toxic (Zhang et al., 2015). Moreover, the other TEs (e.g., Cd, As, $\mathrm{Hg}$, and $\mathrm{Pb}$ ) are extremely toxic to human health (Shah et al., 2012). The literature especially from the Third Pole Region (TPR) underlined mining activities as a potential source of pollution in freshwater bodies that has increased the concentrations of $\mathrm{Cu}$, $\mathrm{Pb}$, and Mn, which poses a high threat to the glacier-fed Himalayan River basins (Huang et al., 2009; Qu et al., 2019).

In general, the glacier-fed river basins of Nepal Himalaya are considered to be pristine (Tripathee et al., 2016). However, recent studies have suggested that long-range transport of pollutants and anthropic contaminations on the freshwater bodies in the region are one of the core scientific questions for environmentalists and water resource managers (Bishwakarma et al., 2019; Pant et al., 2020; Paudyal et al., 2016; Sun et al., 2020). To take effective measures for preventing aquatic pollution and environmental safeguard, a scientific interpretation is greatly required under the context of rapid urbanization and global climate change. Thus, keeping in view of climate change, rapid demographic changes, urbanizations, and ongoing rampant developmental activities in the area, this study aims to: 1) characterize the spatiotemporal variations of TEs; 2) identify the potential sources of pollutants and the level of contaminations, and 3) evaluate the river water quality pertaining to TEs and their potential human and ecological health risks in the Seti River Basin (SRB).

\section{Materials and methods}

\subsection{Study area}

This study was conducted in the Seti River and its major tributaries in the Gandaki Province, Central Himalaya, Nepal (Fig. 1). The Seti River Basin (SRB) is one of the medium-scale freshwater river systems that originated from the glacial-fed region $\left(83^{\circ} 45^{\prime} \mathrm{E}\right.$ to $84^{\circ} 30^{\prime} \mathrm{E}$ and $27^{\circ} 45^{\prime} \mathrm{N}$ to $\left.28^{\circ} 45^{\prime} \mathrm{N}\right)$. The climate of the basin is the sub-tropical to sub-alpine types with intense rainfall (>80\%) during the monsoon season from June to September. The mean rainfall in the middle of the river basin is $5700 \mathrm{~mm}$ per year (Lumle station1740 masl), which is the highest mean rainfall in the country. The great topographical and geological variations are found in the basin, for instance, the low lying areas in the downstream region consists of Mahabharat Range and Lesser Himalayas, whereas the northern in the headwater region is of the higher Himalayas. The upper, middle and lower segments of the SRB consists of high-grade metamorphic rocks including quartzite, schist, and gneiss; phyllites and quartzite; and low-grade sandstones, shales, dolomites, phyllite, and schists, respectively (Fort et al., 2018). It is the main source of water for more than 1 million people residing in core urban area and the vicinity (Rupakheti et al., 2017). 
2.2. Sampling and laboratory analysis

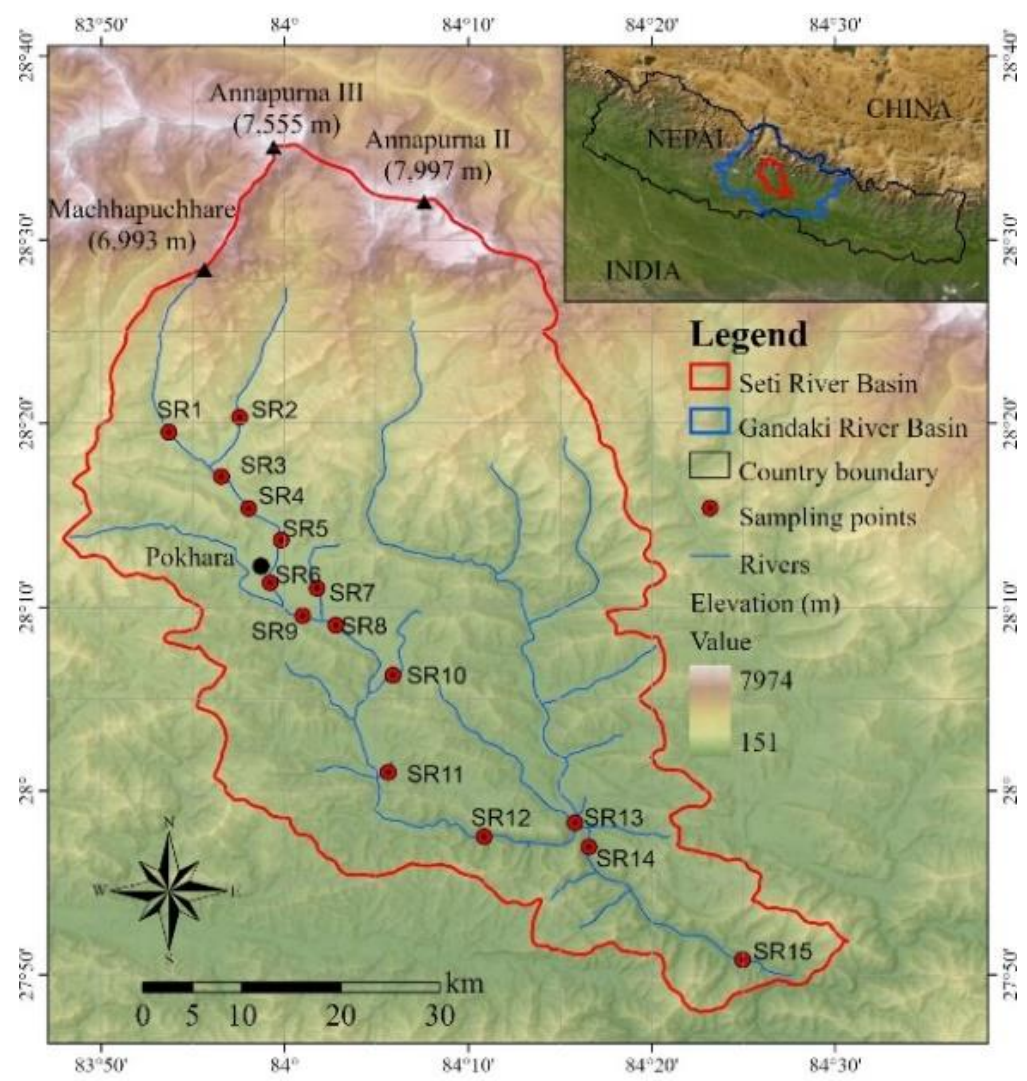

Fig. 1. Sampling points in the Seti River Basin

The composite water samples were collected from 15 different locations from the mainstream of the Seti River and its major tributaries in pre-monsoon, monsoon, and post-monsoon seasons $(3 \times 15=45)$. Water samples were collected from $15 \mathrm{~cm}$ below the surface. The collection of water samples from the different locations in the SRB was based on the major three segments of the basin that is upstream, midstream and downstream. Precisely, the upstream region is more or less pristine in nature, whereas, the midstream segment and downstream segments are highly and moderately urbanized, respectively. The water samples were collected in previously washed high-density polyethylene (HDPE) bottles and filtered using $0.45 \mu \mathrm{m}$ Millipore nitrocellulose filters. For the determination of the TEs a few drops of $\mathrm{HNO}_{3}$ were added $(\mathrm{pH}<2)$ in each of the samples, and stored in a refrigerator at $4^{\circ} \mathrm{C}$ until the laboratory analysis was performed. The $\mathrm{HNO}_{3}$ is a strong oxidizing agent and it helps to breakdown the organic components. The TEs including $\mathrm{As}, \mathrm{Ba}, \mathrm{Cd}, \mathrm{Co}, \mathrm{Cr}, \mathrm{Cs}, \mathrm{Cu}, \mathrm{Li}, \mathrm{Mn}, \mathrm{Ni}, \mathrm{Pb}, \mathrm{Sc}, \mathrm{Sr}, \mathrm{V}$, and $\mathrm{Zn}$ were analyzed following the standard laboratory procedures. The analyses were accompanied at the Institute of Tibetan Plateau Research, Chinese Academy of Sciences (ITP-CAS), Beijing using Inductively Coupled PlasmaMass Spectrometry (ICP-MS, X-7 Thermo Elemental) under standard operating conditions. The detection $(0.047 \mu \mathrm{g} / \mathrm{L}), \mathrm{Cs}(1.776 \mathrm{ng} / \mathrm{L}), \mathrm{Cu}(0.055 \mu \mathrm{g} / \mathrm{L}), \mathrm{Li}(0.065 \mu \mathrm{g} / \mathrm{L}), \mathrm{Mn}(0.063 \mu \mathrm{g} / \mathrm{L}), \mathrm{Ni}(0.007 \mu \mathrm{g} / \mathrm{L}), \mathrm{Pb}$ $(9.567 \mathrm{ng} / \mathrm{L}), \mathrm{Sc}(0.065 \mu \mathrm{g} / \mathrm{L}), \mathrm{Sr}(0.008 \mu \mathrm{g} / \mathrm{L}), \mathrm{V}(0.112 \mu \mathrm{g} / \mathrm{L})$, and $\mathrm{Zn}(0.086 \mu \mathrm{g} / \mathrm{L})$. The accuracy of the analytical protocol was ascertained based on repeated measurement of the externally certified reference solution (Wang et al., 2017). Quality assurance and control were performed using certified external as well as internal standards, and the replicated sample was measurements during the analysis. External standard solutions for all the above-mentioned TEs were prepared from Multi- 
element ICP-MS Calibration Standards. The recovery percentage for the TEs in the standard was between $95 \%-105 \%$.

\subsection{Statistical analyses}

The descriptive statistics and multivariate analyses like cluster analysis (CA) and principal component analysis (PCA) were performed using SPSS version 26.0 to examine the spatiotemporal patterns of TEs in the basin. Particularly, PCA was employed in normalized data set of the TEs concentrations to extract significant principal components (PCs) and identify the possible sources, and potential associations of TEs with each other (Pant et al., 2020; Varol et al., 2013). Hierarchical agglomerative CA was performed to assess the similarities of contaminated locations based on TEs concentrations (Singh et al., 2004).

\subsection{Health risk assessment}

\subsubsection{Water quality index (WQI)}

The WQI acts as a strong medium to evaluate the river water quality by integrating the multiple water quality variables (Acharya et al., 2020). In the present study, the WQI based on $\mathrm{As}, \mathrm{Ba}, \mathrm{Cd}, \mathrm{Co}, \mathrm{Cr}, \mathrm{Cu}, \mathrm{Mn}, \mathrm{Ni}$, $\mathrm{Pb}$, and $\mathrm{Zn}$ were calculated by using the equation (1):

$$
W Q I=\Sigma\left[W i *\left(\frac{C i}{S i}\right)\right] * 100
$$

Where,

$\mathrm{Wi}=\mathrm{wi} / \sum \mathrm{wi}$; wi is the weight of each variable, $\sum$ wi is the sum of the weightings of all variables, $\mathrm{Ci}=$ concentration of each $\mathrm{TE}$ in each water sample, and $\mathrm{Si}=$ World Health Organization Guidelines for Drinking Water (WHO, 2011) for each TE.

The WQI has been classified into five groups depending on the range of its values as; <50, 50-100, 100200, 200-300, and >300 categorized in excellent, good, poor, very poor, and unsuitable, respectively.

\subsubsection{Metal Index (MI)}

MI is an essential tool that describes the possible effects of metals on human health. The MI was calculated by equation (2) (Tamasi and Cini, 2004).

$$
\mathrm{MI}=\sum\left(\frac{\mathrm{C}}{\mathrm{MAC}}\right)
$$

where,

$\mathrm{C}=$ average concentration of metal

MAC $=$ Maximum allowable concentration of metal.

The MI>1 is a threshold of warning for low water quality and thus cannot be used for drinking purposes.

\subsubsection{Health risk assessment (HRA)}

\section{A. Non-carcinogenic risk}

The evaluation of the degree of toxicity of TEs on water bodies is essential for aquatic risk assessments and the determination of the adoption of required actions (Wu et al., 2009). Generally, the amount taken through the digestion and absorbed through the skin is considered for the risk assessment (Ustaoğlu and Tepe, 2019). The HRA models are a widely used method to quantify the potential risk of TEs to the inhabitants consuming water (Tripathee et al., 2016; Wu et al., 2009). U.S. Environmental Protection Agency (USEPA) has recommended that hazard quotient (HQ) and hazard index (HI) for aquatic risk assessment of noncarcinogenic effect, which can be calculated as following equations (Meng et al., 2016):

$$
\begin{aligned}
& \text { ADDingestion }=(C w * I R * E F * E D) /(B W * A T) \\
& A D D \text { dermal }=\left(C w * S A * K p * E T * E D * 10^{-3}\right) /(B W * A T) \\
& H Q=A D D / R f D \\
& H I=\sum H Q s
\end{aligned}
$$


where ADDingestion and ADD dermal are the average daily dose close from ingestion and dermal absorption respectively and are given as $\mu \mathrm{g} \mathrm{kg}^{-1} \mathrm{day}^{-1}$; $\mathrm{Cw}$ is the average trace element concentration in each water sample $\left(\mu \mathrm{g} \mathrm{L}^{-1}\right)$; BW is the average body weight (70 $\mathrm{kg}$ for adults and $15 \mathrm{~kg}$ for children); IR is the ingestion rate ( 2 and $0.64 \mathrm{~L} \mathrm{day}^{-1}$ for adults and children, respectively); $\mathrm{EF}$ is the exposure frequency (350 days year ${ }^{1}$ ); ED is the exposure duration (30 and 6 years for adults and children, respectively); AT is the average time $($ ED $\times 365$ days year-1 $)$; SA is exposed skin area $\left(18,000 \mathrm{~cm}^{2}\right.$ for adults and $6,600 \mathrm{~cm}^{2}$ for children); ET is the exposure time ( 0.58 and $1 \mathrm{~h}$ day $^{-}$for adults and children, respectively); Kp is the dermal permeability coefficient in water $\left(\mathrm{cm} \mathrm{h}^{-1}\right)$; RfD is the corresponding reference dose $\left(\mu \mathrm{g} \mathrm{kg}^{-1} \mathrm{day}^{-1}\right)$. These values were referenced from (US EPA, 2004; Wang et al., 2017). When HQ > 1, a non-carcinogenic effect that can have an adverse effect on human health should be considered (Ustaoğlu and Tepe, 2019).

\section{B. Carcinogenic risk (CR)}

The CR is widely used to evaluate the probability of developing cancer due to the exposure of the chemicals to the people. Only $\mathrm{As}, \mathrm{Cd}, \mathrm{Pb}$, and $\mathrm{Cr}$ are sorted as the cancer-causing elements in this study and calculated using the following equations (Meng et al., 2016):

$$
\begin{aligned}
& \text { CRingestion }=A D \text { Dingestion } / S \\
& C \text { Rdermal }=A D D \text { dermal } / S F \ldots . \\
& C I=\text { CRingestion }+ \text { CRdermal.... }
\end{aligned}
$$

Where,

$\mathrm{SF}$ is the oral cancer slope factor and its values were 0.0015 and $0.00366 \mu \mathrm{g} \mathrm{kg}^{-1} \mathrm{day}^{-1}$ for ingestion and dermal exposure, respectively (Meng et al., 2016).

\section{Results and discussion}

\subsection{General hydrochemistry}

The results of descriptive statistical analysis of the TEs was presented in Table 1. The overall analysis showed that $\mathrm{Cd}$ and $\mathrm{Sr}$ had the lowest and highest mean concentrations, respectively. Overall mean concentration of TEs followed the order: $\mathrm{Cd}<\mathrm{Cs}<\mathrm{V}<\mathrm{Co}<\mathrm{Pb}<\mathrm{Ni}<\mathrm{As}<\mathrm{Sc}<\mathrm{Cr}<\mathrm{Cu}<\mathrm{Mn}<\mathrm{Li}<\mathrm{Ba}$ $<\mathrm{Zn}<\mathrm{Sr}$. Additionally, TEs can be classified into three groups based on the concentration as high $(>10$ $\mu \mathrm{g} / \mathrm{L})$, moderate $(0.1 \mu \mathrm{g} / \mathrm{L}$ to $10 \mu \mathrm{g} / \mathrm{L})$, and low $(<0.1 \mu \mathrm{g} / \mathrm{L})$ (Pant et al., 2020). The Cd was categorized as the low and $\mathrm{Sr}, \mathrm{Zn}$, and $\mathrm{Ba}$ as the high category. The remaining eleven elements ( $\mathrm{Li}, \mathrm{Mn}, \mathrm{Cu}, \mathrm{Cr}, \mathrm{Sc}, \mathrm{As}$, $\mathrm{Ni}, \mathrm{Pb}, \mathrm{Co}, \mathrm{V}$, and $\mathrm{Cs}$ ) belonged to the moderate category. The concentrations of all the measured TEs were within the limits of permissible drinking water quality set by the WHO and hence the environmental quality of the SRB is currently safe from the perspective of TEs contaminations.

\subsection{Spatiotemporal pattern}

The mean concentrations of TEs in this study displayed a great seasonality. The elemental concentration during the pre-monsoon was greater and lower during the monsoon (Table 1). The order of concentration of TEs were $\mathrm{Cd}<\mathrm{Co}<\mathrm{V}<\mathrm{Cs}<\mathrm{Pb}<\mathrm{Ni}<\mathrm{As}<\mathrm{Cu}<\mathrm{Cr}<\mathrm{Mn}<\mathrm{Sc}<\mathrm{Zn}<\mathrm{Li}<\mathrm{Ba}<\mathrm{Sr}$; $\mathrm{Cd}<\mathrm{Cs}<\mathrm{Co}<$ $\mathrm{V}<\mathrm{Pb}<\mathrm{Sc}<\mathrm{Cr}<\mathrm{Ni}<\mathrm{As}<\mathrm{Li}<\mathrm{Mn}<\mathrm{Cu}<\mathrm{Ba}<\mathrm{Zn}<\mathrm{Sr}$ and $\mathrm{Cd}<\mathrm{Cs}<\mathrm{V}<\mathrm{Co}<\mathrm{Pb}<\mathrm{Sc}<\mathrm{Ni}<\mathrm{As}<$ $\mathrm{Cu}<\mathrm{Cr}<\mathrm{Mn}<\mathrm{Li}<\mathrm{Ba}<\mathrm{Zn}<\mathrm{Sr}$ in the pre-monsoon, monsoon, and post-monsoon, respectively. The distinct pattern of TEs with seasonal variations especially for $\mathrm{Zn}, \mathrm{Li}$, etc. could be due to anthropic activities including municipal waste discharge in the river channel. Similar results were also obtained from the previous studies in the lake basin of the SRB (Rupakheti et al., 2017; Sharma et al., 2015).

Importantly, compared with the seasonal basis, the mean concentrations of TEs were relatively low during the monsoon season. This is mainly due to the monsoon driven climatic seasonality in the basin, where $80 \%$ 
187 rainfall occurs from June to September. The heavy rainfall resulted in the consequent reduction of the 188 concentration of TEs in the basin due to the dilution effects. During the season, the heavy rainfall and 189 increasing discharge in the river basin were the most plausible explication for the lowest concentrations of 190 the TEs. Moreover, the rampant urbanization and the seasonal anthropic activities mostly the agricultural 191 practices in the mid and down segments of the river basin during the pre- and post-monsoon seasons elevated 192 the concentrations of TEs in the basin.

193

194 Table 1 Statistical summary of trace elements (TEs) compositions in the Seti River Basin. (Concentration expressed in $\mu \mathrm{g} / \mathrm{L}$ )

\begin{tabular}{|c|c|c|c|c|c|c|c|c|c|c|c|c|c|c|c|c|}
\hline Season & Value & As & $\mathbf{B a}$ & Cd & Co & $\mathrm{Cr}$ & Cs & $\mathrm{Cu}$ & $\mathbf{L i}$ & Mn & $\mathbf{N i}$ & $\mathbf{P b}$ & Sc & $\mathbf{S r}$ & $\mathbf{V}$ & $\mathbf{Z n}$ \\
\hline \multirow{5}{*}{$\begin{array}{l}\text { Pre- } \\
\text { monsoon }\end{array}$} & Min & 0.72 & 10.46 & 0 & 0.07 & 1.31 & 0.09 & 0.67 & 0.44 & 0.1 & 0.34 & 0.04 & 2.75 & 27.56 & 0.14 & 1.21 \\
\hline & Max & 3.67 & 38.44 & 0.35 & 0.23 & 2.91 & 1.44 & 6.52 & 21.55 & 7.73 & 3.44 & 1.7 & 5.02 & 408 & 0.66 & 45.45 \\
\hline & SD & 0.83 & 7.33 & 0.09 & 0.05 & 0.51 & 0.39 & 1.42 & 7.21 & 2.3 & 0.75 & 0.52 & 0.66 & 112.16 & 0.16 & 11.06 \\
\hline & Mean & 1.76 & 19.68 & 0.03 & 0.16 & 2.07 & 0.46 & 1.96 & 7.45 & 3.01 & 1.39 & 0.66 & 3.58 & 210.71 & 0.34 & 6.89 \\
\hline & Min & 0 & 0.06 & 0 & 0.01 & 0.06 & 0.01 & 0.12 & 0 & 0.04 & 0.04 & 0.02 & 0.02 & 0.07 & 0.01 & 0.34 \\
\hline \multirow{3}{*}{ Monsoon } & Max & 1.15 & 23.22 & 0.03 & 0.53 & 0.85 & 0.09 & 17.16 & 2.29 & 5.57 & 2.19 & 0.94 & 0.66 & 73.03 & 0.81 & 18.9 \\
\hline & SD & 0.32 & 6.38 & 0.01 & 0.11 & 0.2 & 0.02 & 4.26 & 0.76 & 1.41 & 0.5 & 0.35 & 0.15 & 18.16 & 0.23 & 4.84 \\
\hline & Mean & 0.57 & 8.45 & 0.01 & 0.2 & 0.4 & 0.05 & 1.92 & 1.01 & 1.46 & 0.47 & 0.36 & 0.38 & 37.08 & 0.26 & 9.28 \\
\hline \multirow{4}{*}{$\begin{array}{l}\text { Post- } \\
\text { monsoon }\end{array}$} & Min & 0.3 & 6.31 & 0.01 & 0.03 & 0.26 & 0 & 0.62 & 0.44 & 0.28 & 0.42 & 0.01 & 0.47 & 18.35 & 0.16 & 1.22 \\
\hline & Max & 2.81 & 48.5 & 0.08 & 4.7 & 11.35 & 0.94 & 5.23 & 13.46 & 7.01 & 5.56 & 1.96 & 1.1 & 198.4 & 0.51 & 264.2 \\
\hline & SD & 0.68 & 9.62 & 0.02 & 1.21 & 2.65 & 0.29 & 1.31 & 3.79 & 1.77 & 1.25 & 0.6 & 0.17 & 57.96 & 0.09 & 85.2 \\
\hline & Mean & 1.29 & 18.05 & 0.03 & 0.78 & 2.46 & 0.2 & 2 & 4.22 & 3.2 & 1.24 & 0.82 & 0.85 & 120.51 & 0.31 & 98.87 \\
\hline & Min & 0 & 0.06 & 0 & 0.01 & 0.06 & 0.01 & 0.12 & 0 & 0.04 & 0.04 & 0.01 & 0.02 & 0.07 & 0.01 & 0.34 \\
\hline Grand & Max & 3.67 & 48.5 & 0.35 & 4.7 & 11.35 & 1.44 & 17.16 & 21.55 & 7.73 & 5.56 & 1.96 & 5.02 & 408 & 0.81 & 264.2 \\
\hline \multirow[t]{2}{*}{ Mean } & $\mathrm{SD}$ & 0.8 & 9.2 & 0.05 & 0.74 & 1.77 & 0.33 & 2.64 & 5.33 & 1.98 & 0.96 & 0.53 & 1.48 & 101.58 & 0.17 & 65.04 \\
\hline & Mean & 1.21 & 15.39 & 0.02 & 0.38 & 1.65 & 0.27 & 1.96 & 4.23 & 2.56 & 1.03 & 0.61 & 1.6 & 122.77 & 0.31 & 38.35 \\
\hline $\begin{array}{l}\text { Global } \\
\text { average }\end{array}$ & & 0.62 & 23 & 0.08 & 0.14 & 0.70 & 0.01 & 1.48 & 1.84 & 34 & 0.80 & 0.08 & 1.20 & 60 & 0.71 & 0.60 \\
\hline $\begin{array}{l}\text { WHO } \\
\text { Limit** }^{*}\end{array}$ & & 10 & 700 & 3 & - & 50 & - & 2000 & - & 400 & 70 & 10 & - & - & - & 1000 \\
\hline
\end{tabular}

$195 *$ (Gaillardet et al., 2014);**(WHO, 2011)

196 3.3. Principal component analysis (PCA)

197 In this study, six principal components (PCs) with eigenvalues $>1$ explained $78.48 \%$ of the total variance 198 (Fig. 2). PC1 accounted for $17.33 \%$ of the total variance, had strong loadings on Mn and Ni; and moderately 199 loadings on $\mathrm{Pb}$ and $\mathrm{Zn}$. The PC1 TEs might be originated from anthropic inputs such as agricultural runoff 200 and domestic effluents (Wang et al., 2017). Similarly, PC2 explained $14.82 \%$ of the total variance, had 201 strong loading on Sc and Sr, which were associated with the crustal sources. PC3 accounted for $14.49 \%$ of 202 total variance showing the strong loadings on $\mathrm{Cs}$ and $\mathrm{Li}$ and moderate loadings on As which were associated 203 with the rock weathering and pedogenic activities. Likewise, the PC4 had $12.49 \%$ of total variance with 204 the strong loadings on Ba and Co representing mixed sources of origin. PC5 and PC6 covered $10.09 \%$ and $2058.57 \%$ of the total variance, respectively. The PC5 had strong loadings on Cu and V; whereas the PC6 had 206 strong loadings on Cd. The loadings of TEs on PC5 and PC6 exhibited the probability that these elements 207 were originated from anthropic sources. The results of PCA indicated that the natural geological weathering 208 processes had a crucial role in determining the TEs compositions in the SRB with minor signatures of 209 anthropic interferences. 


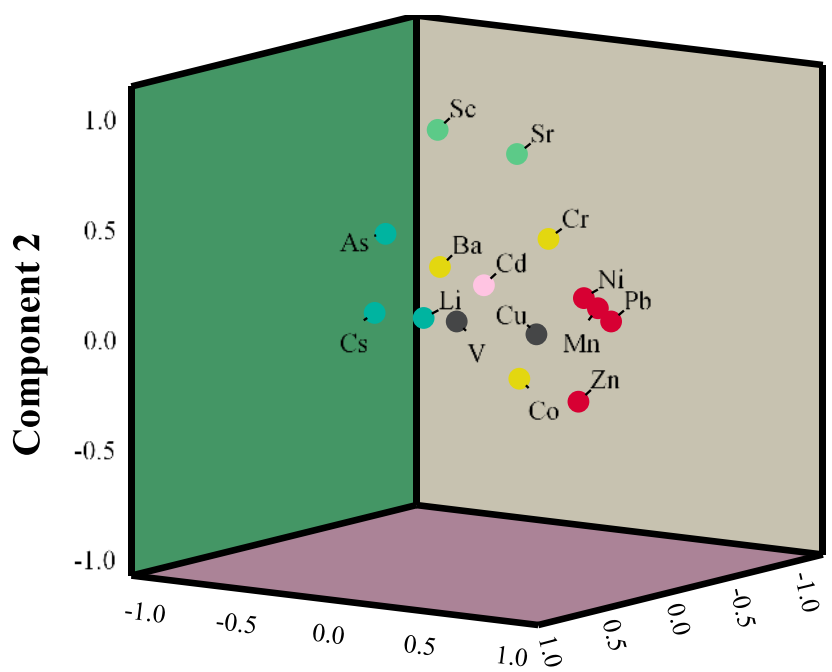

\section{Component 1 \\ Component 3}

Fig. 2. Plotting of principal component analysis of dissolved trace elements (TEs) in the Seti River Basin.

3.4. Cluster analysis (CA)

CA was applied to a group of similar sampling sites and evaluate the relative contamination site in the study area (Varol, 2011). In this study, Ward's method with squared Euclidean distance successfully adopted all samples ( $\mathrm{n}=45)$ collected in three distinct seasons from the SRB (Fig. 3). Cluster 1, 2 and 3 comprised 60\%, $17.80 \%$ and $22.20 \%$ sampling points, characterizing relatively low, medium, and high TEs concentrations, respectively. The water samples associated with cluster 1 were from the monsoon season $(n=15)$. In addition, $33.33 \%$ and $46.66 \%$ samples were also grouped in cluster 1 from the pre-and post-monsoon season, respectively. The majority of sampling points grouped in cluster 1 representing either headwater or in the downstream region indicating that the relatively less contamination in those areas as compared to midstream segment. Cluster 2 included water samples from the post-monsoon season indicating the moderate contamination during the period. The effect of anthropic activities along with low dilution could be the reasons for the clustering of sampling points in cluster 2. Finally, cluster 3 included all water samples from the pre-monsoon season indicating relatively high contamination during the period. In addition, due to low river flow and high land-water interaction along with anthropic activities could be the possible reasons for the elevated concentration of TEs grouped in cluster 3. The results indicated that the temporal patterns of water quality were not always consistent and approving that the governing factors of river water quality in one environment might not be significant in another due to profound seasonality and distinct anthropic interferences. 


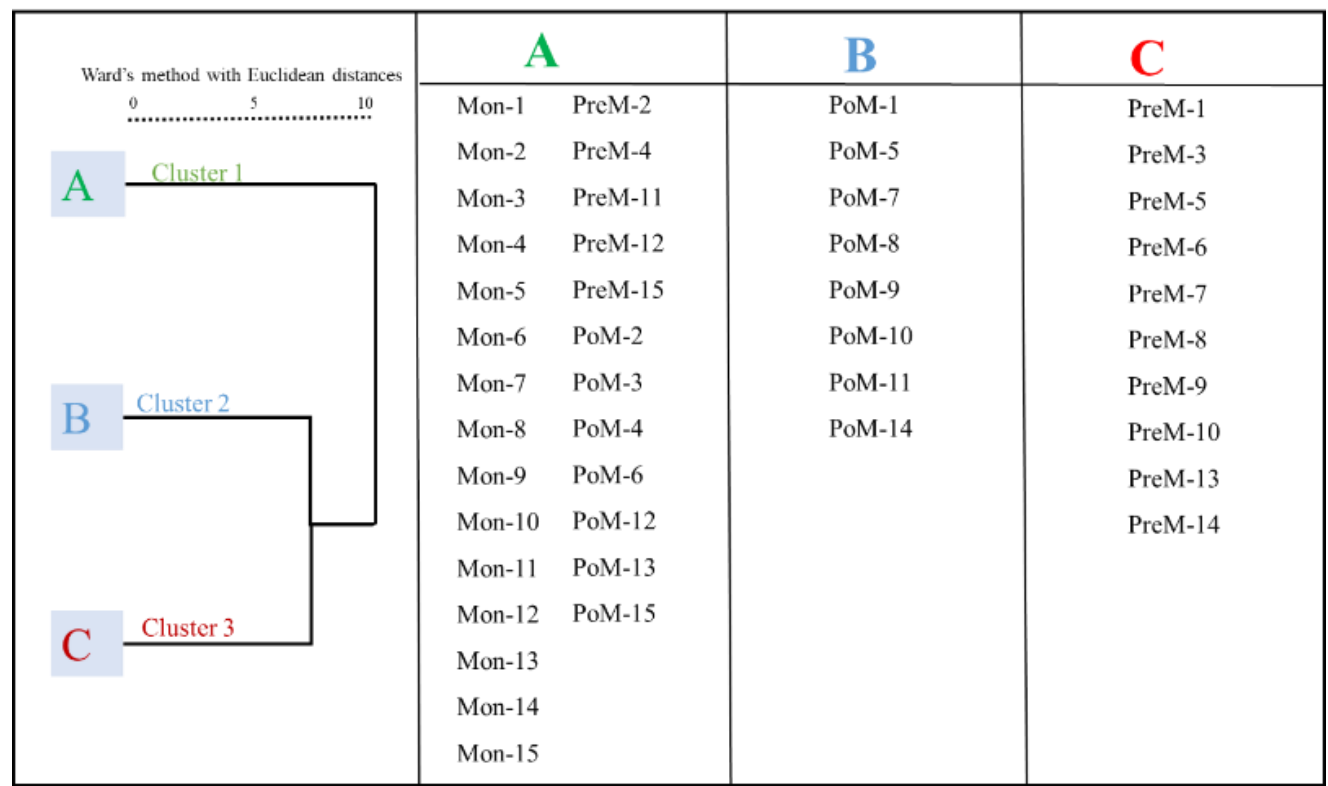

Fig. 3. Hierarchical clustering of sampling sites on dendrogram in the Seti River Basin.

3.5. Water Quality Index (WQI) and Metal Index (MI)

The overall WQI of the SRB in the pre-monsoon, monsoon, and post-monsoon were 4.82, 1.76, and 4.57, respectively. The results indicated that WQI in all the seasons was $<50$ exhibiting that the riverine environment is still safe from contamination and water is suitable for drinking purposes based on the selected dissolved TEs (Table 2). The seasonal comparison of WQI showed that the monsoon season had relatively better water quality followed by the post-monsoon and pre-monsoon seasons. This might be due to a decrease in the concentration of TEs in the monsoon season owing to the dilution effect of the rainfallrunoff (Pant et al., 2020).

In this study, the MI value for all seasons was <0.5, i.e., $0.36,0.14$, and 0.37 for the pre-monsoon, monsoon, and post-monsoon, respectively (Table 2). It was considered that the riverine environment is safe when the MI value is <1 (Rupakheti et al., 2017). This indicated that the water of the SRB exhibited safe for drinking in all seasons in terms of the TEs. The seasonal comparison MI showed that monsoon season had relatively better water quality followed by pre-monsoon and post-monsoon seasons.

Table 2 Water Quality Index (WQI) and Metal Index (MI) of the Seti River Basin.

\begin{tabular}{|c|c|c|c|c|c|c|c|c|c|c|c|}
\hline \multirow{2}{*}{ Elements } & \multirow{2}{*}{ wi } & \multirow{2}{*}{ Wi } & \multirow{2}{*}{ Si } & \multicolumn{2}{|c|}{ Pre-monsoon } & \multicolumn{2}{|c|}{ Monsoon } & \multicolumn{2}{|c|}{ Post-monsoon } & \multicolumn{2}{|c|}{ Overall } \\
\hline & & & & WQI & MI & WQI & MI & WQI & MI & WQI & MI \\
\hline As & 5.00 & 0.15 & 10.00 & 2.67 & 0.18 & 0.87 & 0.06 & 1.96 & 0.13 & 1.83 & 0.12 \\
\hline $\mathbf{B a}$ & 2.00 & 0.06 & 700.00 & 0.17 & 0.03 & 0.07 & 0.01 & 0.16 & 0.03 & 0.13 & 0.02 \\
\hline Cd & 5.00 & 0.15 & 3.00 & 0.16 & 0.01 & 0.06 & 0.00 & 0.13 & 0.01 & 0.12 & 0.01 \\
\hline Co & 1.00 & 0.03 & 50.00 & 0.01 & 0.00 & 0.01 & 0.00 & 0.05 & 0.02 & 0.02 & 0.01 \\
\hline $\mathrm{Cr}$ & 5.00 & 0.15 & 50.00 & 0.63 & 0.04 & 0.12 & 0.01 & 0.75 & 0.05 & 0.50 & 0.03 \\
\hline $\mathbf{C u}$ & 2.00 & 0.06 & 2000.00 & 0.01 & 0.00 & 0.01 & 0.00 & 0.01 & 0.00 & 0.01 & 0.00 \\
\hline Mn & 5.00 & 0.15 & 400.00 & 0.11 & 0.01 & 0.06 & 0.00 & 0.12 & 0.01 & 0.10 & 0.01 \\
\hline $\mathbf{N i}$ & 1.00 & 0.03 & 70.00 & 0.06 & 0.02 & 0.02 & 0.01 & 0.05 & 0.02 & 0.04 & 0.01 \\
\hline $\mathbf{P b}$ & 5.00 & 0.15 & 10.00 & 0.99 & 0.07 & 0.54 & 0.04 & 1.24 & 0.08 & 0.93 & 0.06 \\
\hline $\mathbf{Z n}$ & 1.00 & 0.03 & 3000.00 & 0.01 & 0.00 & 0.01 & 0.00 & 0.10 & 0.03 & 0.04 & 0.01 \\
\hline Total & 33.00 & & & 4.82 & 0.36 & 1.76 & 0.14 & 4.57 & 0.37 & 3.72 & 0.29 \\
\hline
\end{tabular}


3.6. Hazard Index (HI) and Cancer Index (CI)

249 The carcinogenic and non-carcinogenic risks of $\mathrm{As}, \mathrm{Ba}, \mathrm{Cd}, \mathrm{Co}, \mathrm{Cr}, \mathrm{Cu}, \mathrm{Mn}, \mathrm{Ni}, \mathrm{Pb}$, and $\mathrm{Zn}(\mathrm{Cs}, \mathrm{Li}, \mathrm{Sc}, \mathrm{Sr}$, 250 and $\mathrm{V}$ excluded owing to the unavailability of standards value) were calculated based on health risk 251 assessment model recommended by the USEPA (Table 3). The results showed that the hazard quotient (HQ) 252 and HI values for adults and children by the ingestion and dermal pathways for both adults and children was $253<1$ for all ten measured TEs. Likewise, the HI value for both adults and children was within the safe limit. 254 Among the TEs, the $\mathrm{HI}$ followed the order: $\mathrm{As}>\mathrm{Co}>\mathrm{Cr}>\mathrm{Pb}>\mathrm{Zn}>\mathrm{Mn}>\mathrm{Ba}>\mathrm{Ni}>\mathrm{Cd}>\mathrm{Cu}$ for adults 255 and $\mathrm{As}>\mathrm{Co}>\mathrm{Cr}>\mathrm{Pb}>\mathrm{Mn}>\mathrm{Zn}>\mathrm{Ba}>\mathrm{Cd}>\mathrm{Ni}>\mathrm{Cu}$ for children and it was indicated that As had the 256 highest value of $\mathrm{HI}$ for both adults and children. Though the minimal concentration of TEs is essential to 257 health, prolonged exposure with a higher concentration of these elements in drinking water may lead to 258 different health disorders including neurological problems.

259 Table 3 Hazard Quotient (HQ) and Hazard Index (HI) for adults and children for each element in the Seti River Basin.

\begin{tabular}{|c|c|c|c|c|c|c|c|c|c|}
\hline \multirow{2}{*}{ TEs } & \multirow{2}{*}{$\mathbf{K p}$} & \multirow{2}{*}{$\mathbf{R f D}_{\text {ing }}$} & \multirow{2}{*}{$\mathbf{R f D}_{\text {der }}$} & \multicolumn{2}{|l|}{ HQ ing } & \multicolumn{2}{|l|}{ HQ der } & \multicolumn{2}{|l|}{ HI } \\
\hline & & & & Adult & Child & Adult & Child & Adult & Child \\
\hline As & $1.00 \times 10^{-3}$ & 0.3 & 0.12 & $1.10 \times 10^{-1}$ & $1.64 \times 10^{-1}$ & $1.41 \times 10^{-3}$ & $4.15 \times 10^{-3}$ & $1.12 \times 10^{-1}$ & $1.69 \times 10^{-1}$ \\
\hline $\mathbf{B a}$ & $1.00 \times 10^{-3}$ & 200 & 14 & $2.00 \times 10^{-3}$ & $3.00 \times 10^{-3}$ & $1.60 \times 10^{-4}$ & $4.60 \times 10^{-4}$ & $2.27 \times 10^{-3}$ & $3.61 \times 10^{-3}$ \\
\hline Cd & $1.00 \times 10^{-3}$ & 0.5 & 0.02 & $1.00 \times 10^{-3}$ & $1.00 \times 10^{-3}$ & $1.30 \times 10^{-4}$ & $3.90 \times 10^{-4}$ & $1.40 \times 10^{-3}$ & $2.28 \times 10^{-3}$ \\
\hline Co & $4.00 \times 10^{-4}$ & 0.3 & 0.06 & $3.40 \times 10^{-2}$ & $5.10 \times 10^{-2}$ & $3.60 \times 10^{-4}$ & $1.07 \times 10^{-3}$ & $3.50 \times 10^{-2}$ & $5.28 \times 10^{-2}$ \\
\hline $\mathrm{Cr}$ & $1.00 \times 10^{-3}$ & 3 & 0.07 & $1.50 \times 10^{-2}$ & $2.20 \times 10^{-2}$ & $3.14 \times 10^{-3}$ & $9.26 \times 10^{-3}$ & $1.82 \times 10^{-2}$ & $3.17 \times 10^{-2}$ \\
\hline $\mathbf{C u}$ & $1.00 \times 10^{-3}$ & 40 & 8 & $1.00 \times 10^{-3}$ & $2.00 \times 10^{-3}$ & $4.00 \times 10^{-5}$ & $1.00 \times 10^{-4}$ & $1.38 \times 10^{-3}$ & $2.11 \times 10^{-3}$ \\
\hline Mn & $1.00 \times 10^{-3}$ & 24 & 0.96 & $2.00 \times 10^{-3}$ & $4.00 \times 10^{-3}$ & $3.80 \times 10^{-4}$ & $1.12 \times 10^{-3}$ & $3.30 \times 10^{-3}$ & $5.48 \times 10^{-3}$ \\
\hline $\mathbf{N i}$ & $2.00 \times 10^{-4}$ & 20 & 0.8 & $1.00 \times 10^{-3}$ & $2.00 \times 10^{-3}$ & $4.00 \times 10^{-5}$ & $1.10 \times 10^{-4}$ & $1.45 \times 10^{-3}$ & $2.22 \times 10^{-3}$ \\
\hline $\mathbf{P b}$ & $1.00 \times 10^{-4}$ & 1.4 & 0.42 & $1.10 \times 10^{-2}$ & $1.70 \times 10^{-2}$ & $2.00 \times 10^{-5}$ & $6.00 \times 10^{-5}$ & $1.20 \times 10^{-2}$ & $1.79 \times 10^{-2}$ \\
\hline $\mathbf{Z n}$ & $6.00 \times 10^{-4}$ & 300 & 60 & $3.00 \times 10^{-3}$ & $5.00 \times 10^{-3}$ & $5.00 \times 10^{-5}$ & $1.60 \times 10^{-4}$ & $3.56 \times 10^{-3}$ & $5.39 \times 10^{-3}$ \\
\hline
\end{tabular}

261 Likewise, Table 4 showed the CI for both adults and children for the cancer-causing metals likes As, Cd, $262 \mathrm{~Pb}$, and $\mathrm{Cr}$. The cancer risk (CR) via both ingestion and the dermal medium was high for the children than 263 the adults (Meng et al., 2016). Also, the CI was high for the children than adults which showed that the 264 children were more vulnerable to the carcinogenic effect of TEs. The order of CI for both adults and children 265 followed the order: $\mathrm{Cd}<\mathrm{Pb}<\mathrm{As}<\mathrm{Cr}$. Since the values of CIs for adults and children were within the safe 266 limit of the USEPA $\left(10^{-6}-10^{-4}\right)$, indicating that there was little risk of carcinogenicity. Importantly, As, Cd 267 and $\mathrm{Pb}$; and $\mathrm{Cr}$ had low and medium CR, respectively (Iqbal and Shah, 2013).

268 Table 4 Cancer Risk (CR) and Cancer Index (CI) for selective trace elements (TEs) in the Seti River Basin.

\begin{tabular}{ccccccc}
\hline \multirow{2}{*}{ Elements } & \multicolumn{2}{c}{ CR ingestion } & \multicolumn{2}{c}{ CR dermal } & \multicolumn{2}{c}{ CI } \\
\cline { 2 - 7 } & Adult & Child & Adult & Child & Adult & Child \\
\hline As & $4.97 \times 10^{-5}$ & $7.42 \times 10^{-5}$ & $6.33 \times 10^{-7}$ & $1.87 \times 10^{-6}$ & $5.03 \times 10^{-5}$ & $7.61 \times 10^{-5}$ \\
Cd & $9.49 \times 10^{-7}$ & $1.42 \times 10^{-6}$ & $1.21 \times 10^{-8}$ & $3.57 \times 10^{-8}$ & $9.61 \times 10^{-7}$ & $1.45 \times 10^{-6}$ \\
Pb & $2.51 \times 10^{-5}$ & $3.75 \times 10^{-5}$ & $3.20 \times 10^{-8}$ & $9.44 \times 10^{-8}$ & $2.51 \times 10^{-5}$ & $3.76 \times 10^{-5}$ \\
Cr & $6.76 \times 10^{-5}$ & $1.01 \times 10^{-4}$ & $8.61 \times 10^{-7}$ & $2.54 \times 10^{-6}$ & $6.85 \times 10^{-5}$ & $1.04 \times 10^{-4}$ \\
\hline
\end{tabular}




\section{Conclusion}

This study investigates the seasonal variations and health risks of trace elements (TEs) and their environmental significance in the Seti River Basin (SRB), Gandaki Province Nepal. The TEs concentrations followed the distinct monsoon driven climatic seasonality with the dominancy pattern of the elements as pre-monsoon> post-monsoon> monsoon. The PCA results revealed that Sc, Sr, Li, Cs, As, Ba, and Co were primarily controlled by mainly natural sources particularly from the rock weathering and lithogenic, whereas, $\mathrm{Pb}, \mathrm{Zn}, \mathrm{Cu}, \mathrm{V}$, and $\mathrm{Cd}$ were derived from both anthropic sources particularly from the industrial and agricultural effluents. Overall, the natural geological weathering processes had a crucial role in determining the TEs compositions in the SRB with minor signatures of anthropic interferences. Furthermore, the cluster analysis revealed that the TEs concentrations in one environment may not be significant to another. In addition, the water quality index (WQI) of the SRB in the study seasons were markedly low i.e., <5 representing the excellent water quality in the basin, and the metal index (MI) were $<1$ indicating suitability of water for drinking purposes based on selected TEs. Furthermore, the hazard index (HI) values for both adults and children were <1, which showed that there was no non-carcinogenic risk associated with the measured TEs. Similarly, the values of cancer index (CI) for adults and children were within the safe limit. Noticeably, $\mathrm{As}, \mathrm{Cd}$ and $\mathrm{Pb}$; and $\mathrm{Cr}$ had low and medium cancer risk, respectively in the SRB. The findings of this study concluded that the water quality issues in terms of TEs in the SRB may not be a serious concern at present, however, under the context of global climate change, rampant urbanizations and industrialization might be the issues concerning the water quality in the future. Thus, in-depth study in the river basin focusing at the spatiotemporal level is recommended for maintaining the water quality and the ecological integrity of water quality in the SRB, Central Himalaya Nepal.

\section{Acknowledgments}

The authors would like to thank Professor Dr. Zhang Fan for supporting the laboratory analysis of the trace elements samples in the Institute of Tibetan Plateau Research, Chinese Academy of Sciences, China. The authors are also grateful to Dr. Subash Adhikari for supporting the sample collection. In addition, we acknowledge the Central Department of Environmental Science, Institute of Science and Technology, Tribhuvan University, Nepal for providing partial laboratory support and making a conducive environment for this research work.

Author Contributions: Conceptualization and data collection: R.R.P.; lab work: R.R.P. and F.U.R.Q.; data analysis: F.U.R.Q. and K.B.; writing of the original manuscript: R.R.P., K.B., J.N., and S.P.; review and editing: M.B.C., K.B.P., L.B.T., and G.W. All authors have approved the final version of the manuscript.

Funding: This research did not receive any specific grant from funding agencies in the public, commercial, or notfor-profit sectors.

Conflicts of Interest: There is no potential conflict of interest.

\section{References}

Acharya, A., Sharma, M.L., Bishwakarma, K., Dahal, P., Kumar, S., Chaudhari, Adhikari, B., Neupane, S., Pokhrel, B.N., Pant, R.R., 2020. Chemical Characteristics of the Karmanasha River Water and Its Appropriateness for Irrigational Usage. J. Nepal Chem. Soc. 41, 94-102. https://doi.org/10.3126/jncs.v41i1.30494

Bishwakarma, K., Pant, R. R., Pal, K. B., Ghimire, A., Thapa, L. B., Saud, P., Joshi, S., \& Panthi, K. P.,2019. Water quality and land use/cover changes in the Phewa Watershed, Gandaki Province, Nepal. Nepal Journal of Environmental Science, 7, 31-39. https://doi.org/10.3126/njes.v7i0.34473

Fort, M., Adhikari, B.R., Rimal, B., 2018. Pokhara (central nepal): A dramatic yet geomorphologically active environment versus a dynamic, rapidly developing city, Urban Geomorphology: Landforms and Processes in Cities. Elsevier Inc. https://doi.org/10.1016/B978-0-12-811951-8.00012-6

Gaillardet, J., Viers, J., Dupré, B., 2014. Trace Elements in River Waters, in: Treatise on Geochemistry: Second 
Edition. Elsevier, pp. 195-235. https://doi.org/10.1016/B978-0-08-095975-7.00507-6

Huang, X., Sillanpää, M., Gjessing, E.T., Vogt, R.D., 2009. Water quality in the Tibetan Plateau: Major ions and trace elements in the headwaters of four major Asian rivers. Sci. Total Environ. 407, 6242-6254. https://doi.org/10.1016/j.scitotenv.2009.09.001

Iqbal, J., Shah, M.H., 2013. Health Risk Assessment of Metals in Surface Water from Freshwater Source Lakes, Pakistan. Hum. Ecol. Risk Assess. 19, 1530-1543. https://doi.org/10.1080/10807039.2012.716681

Li, S., Zhang, Q., 2010. Risk assessment and seasonal variations of dissolved trace elements and heavy metals in the Upper Han River, China. J. Hazard. Mater. 181, 1051-1058. https://doi.org/10.1016/j.jhazmat.2010.05.120

Li, S., Zhang, Q., 2008. Geochemistry of the upper Han River basin, China, 1: Spatial distribution of major ion compositions and their controlling factors. Appl. Geochemistry 23, 3535-3544. https://doi.org/10.1016/j.apgeochem.2008.08.012

Meng, Q., Zhang, J., Zhang, Z., Wu, T., 2016. Geochemistry of dissolved trace elements and heavy metals in the Dan River Drainage (China): distribution, sources, and water quality assessment. Environ. Sci. Pollut. Res. 23, 8091-8103. https://doi.org/10.1007/s11356-016-6074-x

Pant, R.R., Zhang, F., Rehman, F.U., Koirala, M., Rijal, K., Maskey, R., 2020. Spatiotemporal characterization of dissolved trace elements in the Gandaki River, Central Himalaya Nepal. J. Hazard. Mater. 389, 121913. https://doi.org/10.1016/j.jhazmat.2019.121913

Paudyal, R., Kang, S., Sharma, C.M., Tripathee, L., Huang, J., Rupakheti, D., Sillanpää, M., 2016. Major ions and trace elements of two selected rivers near Everest region, southern Himalayas, Nepal. Environ. Earth Sci. 75, 1-11. https://doi.org/10.1007/s12665-015-4811-y

Qu, B., Zhang, Y., Kang, S., Sillanpää, M., 2019. Water quality in the Tibetan Plateau: Major ions and trace elements in rivers of the "Water Tower of Asia." Sci. Total Environ. 649, 571-581. https://doi.org/10.1016/j.scitotenv.2018.08.316

Rupakheti, D., Tripathee, L., Kang, S., Sharma, C.M., Paudyal, R., Sillanpää, M., 2017. Assessment of water quality and health risks for toxic trace elements in urban Phewa and remote Gosainkunda lakes, Nepal. Hum. Ecol. Risk Assess. 23, 959-973. https://doi.org/10.1080/10807039.2017.1292117

Schwanghart, W., Bernhardt, A., Stolle, A., Hoelzmann, P., Adhikari, B.R., Andermann, C., Tofelde, S., Merchel, S., Rugel, G., Fort, M., Korup, O., 2016. Repeated catastrophic valley infill following medieval earthquakes in the Nepal Himalaya. Science (80-. ). 351, 147-150. https://doi.org/10.1126/science.aac9865

Shah, M.T., Ara, J., Muhammad, S., Khan, S., Tariq, S., 2012. Health risk assessment via surface water and subsurface water consumption in the mafic and ultramafic terrain, Mohmand agency, northern Pakistan. J. Geochemical Explor. 118, 60-67. https://doi.org/10.1016/j.gexplo.2012.04.008

Sharma, C.M., Kang, S., Sillanpää, M., Li, Q., Zhang, Q., Huang, J., Tripathee, L., Sharma, S., Paudyal, R., 2015. Mercury and selected trace elements from a remote (gosainkunda) and an urban (Phewa) Lake Waters of Nepal. Water. Air. Soil Pollut. 226. https://doi.org/10.1007/s11270-014-2276-3

Singh, K.P., Malik, A., Mohan, D., Sinha, S., 2004. Multivariate statistical techniques for the evaluation of spatial and temporal variations in water quality of Gomti River (India) - A case study. Water Res. 38, 3980-3992. https://doi.org/10.1016/j.watres.2004.06.011

Stolle, A., Bernhardt, A., Schwanghart, W., Hoelzmann, P., Adhikari, B.R., Fort, M., Korup, O., 2017. Catastrophic valley fills record large Himalayan earthquakes, Pokhara, Nepal. Quat. Sci. Rev. 177, 88-103. https://doi.org/10.1016/j.quascirev.2017.10.015

Sun, X., Zhang, Q., Li, M., Kandel, K., Rawat, B., Pandey, A., Guo, J., Kang, S., Pant, R.R., Cong, Z., Zhang, F., 2020. Mercury variation and export in trans-Himalayan rivers: Insights from field observations in the Koshi River. Sci. Total Environ. 738, 139836. https://doi.org/10.1016/j.scitotenv.2020.139836

Tamasi, G., Cini, R., 2004. Heavy metals in drinking waters from Mount Amiata (Tuscany, Italy). Possible risks from arsenic for public health in the Province of Siena. Sci. Total Environ. 327, 41-51. https://doi.org/10.1016/j.scitotenv.2003.10.011

Tripathee, L., Kang, S., Sharma, C.M., Rupakheti, D., Paudyal, R., Huang, J., Sillanpää, M., 2016. Preliminary Health Risk Assessment of Potentially Toxic Metals in Surface Water of the Himalayan Rivers, Nepal. Bull. Environ. Contam. Toxicol. 97, 855-862. https://doi.org/10.1007/s00128-016-1945-x

Upreti, B.N., 1999. An overview of the stratigraphy and tectonics of the Nepal Himalaya. J. Asian Earth Sci. 17, 577-606. https://doi.org/10.1016/S1367-9120(99)00047-4 
US EPA, 2004. Air quality criteria for particulate matter.

Ustaoğlu, F., Tepe, Y., 2019. Water quality and sediment contamination assessment of Pazarsuyu Stream, Turkey using multivariate statistical methods and pollution indicators. Int. Soil Water Conserv. Res. 7, 47-56. https://doi.org/10.1016/j.iswcr.2018.09.001

Varol, M., 2011. Assessment of heavy metal contamination in sediments of the Tigris River (Turkey) using pollution indices and multivariate statistical techniques. J. Hazard. Mater. 195, 355-364. https://doi.org/10.1016/j.jhazmat.2011.08.051

Varol, M., Gökot, B., Bekleyen, A., 2013. Dissolved heavy metals in the Tigris River (Turkey): Spatial and temporal variations. Environ. Sci. Pollut. Res. 20, 6096-6108. https://doi.org/10.1007/s11356-013-1627-8

Wang, G., Zeng, C., Zhang, F., Zhang, Y., Scott, C.A., Yan, X., 2017. Traffic-related trace elements in soils along six highway segments on the Tibetan Plateau: Influence factors and spatial variation. Sci. Total Environ. 581582, 811-821. https://doi.org/10.1016/j.scitotenv.2017.01.018

Wang, J., Liu, G., Liu, H., Lam, P.K.S., 2017. Multivariate statistical evaluation of dissolved trace elements and a water quality assessment in the middle reaches of Huaihe River, Anhui, China. Sci. Total Environ. 583, 421431. https://doi.org/10.1016/j.scitotenv.2017.01.088

WHO, 2011. Guidelines for Drinking-water Quality.

Wu, B., Zhao, D.Y., Jia, H.Y., Zhang, Y., Zhang, X.X., Cheng, S.P., 2009. Preliminary risk assessment of trace metal pollution in surface water from Yangtze River in Nanjing section, China. Bull. Environ. Contam. Toxicol. 82, 405-409. https://doi.org/10.1007/s00128-008-9497-3

Zhang, Y., Sillanpää, M., Li, C., Guo, J., Qu, B., Kang, S., 2015. River water quality across the Himalayan regions: elemental concentrations in headwaters of Yarlung Tsangbo, Indus and Ganges River. Environ. Earth Sci. 73, 4151-4163. https://doi.org/10.1007/s12665-014-3702-y 


\section{Figures}

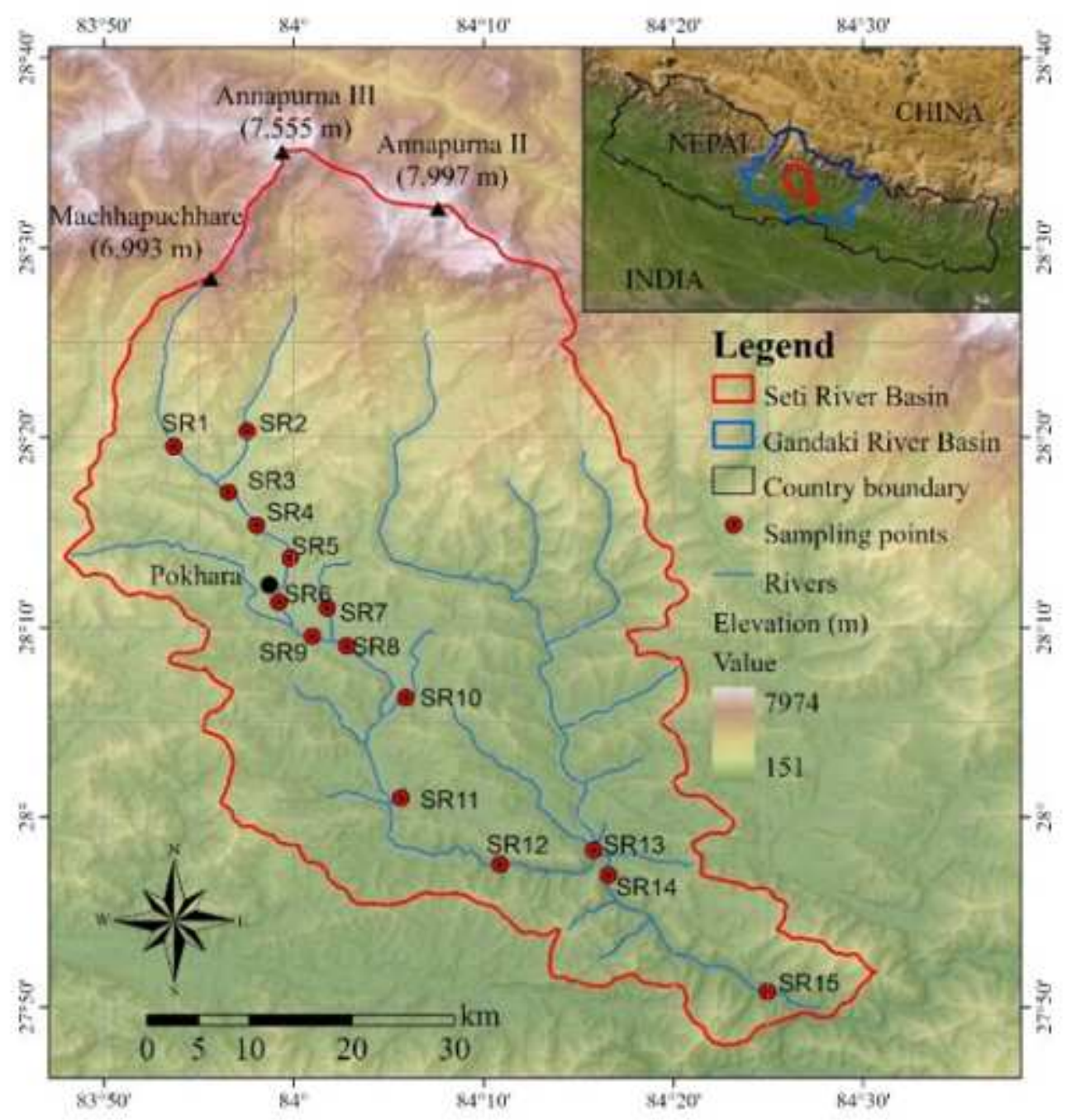

\section{Figure 1}

Sampling points in the Seti River Basin. Note: The designations employed and the presentation of the material on this map do not imply the expression of any opinion whatsoever on the part of Research Square concerning the legal status of any country, territory, city or area or of its authorities, or concerning the delimitation of its frontiers or boundaries. This map has been provided by the authors. 


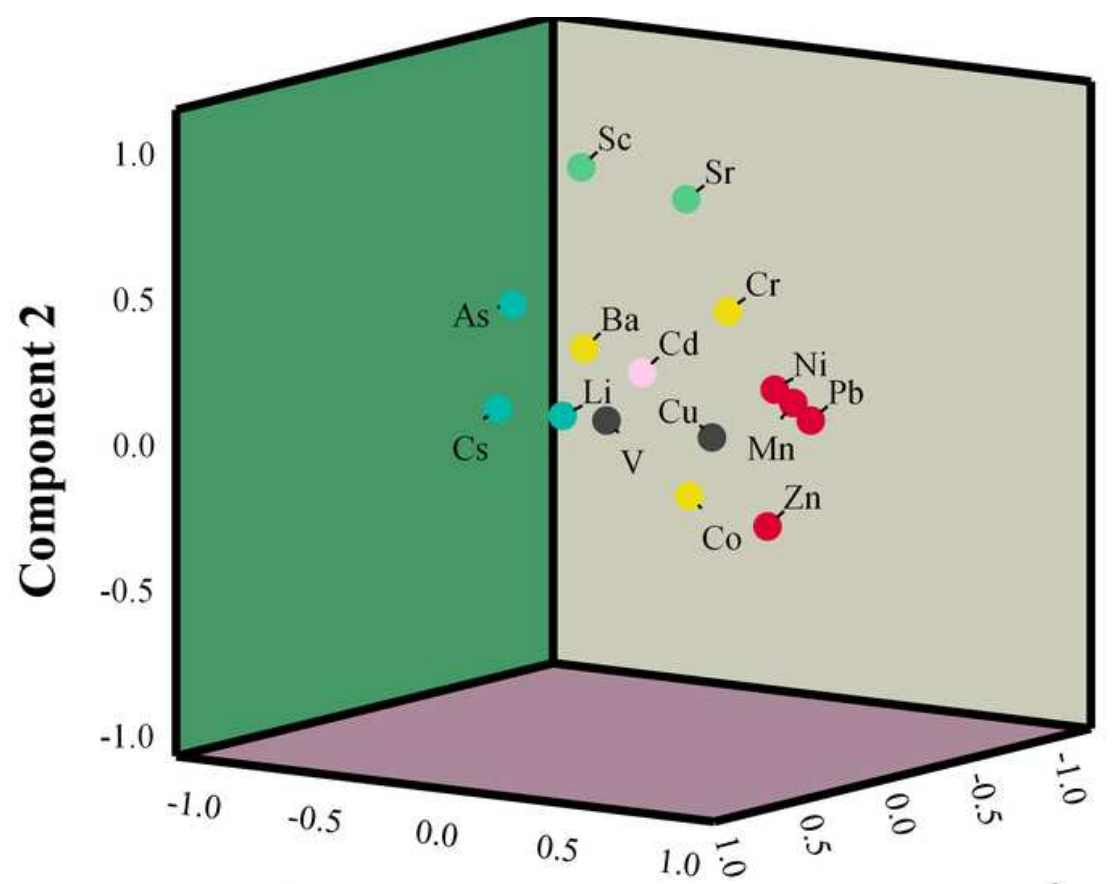

Component 1

component 3

Figure 2

Plotting of principal component analysis of dissolved trace elements (TEs) in the Seti River Basin.

\begin{tabular}{|c|c|c|c|c|c|}
\hline \multirow{2}{*}{\multicolumn{2}{|c|}{ Wian's method with Eachicean distances }} & \multicolumn{2}{|c|}{$\mathbf{A}$} & B & C \\
\hline & & Mon-1 & PreM-2 & PoM-1 & PreM-1 \\
\hline & Cluster I & Mon-2 & PreM-4 & PoM-5 & PreM-3 \\
\hline & \multirow{5}{*}{ Cluster 2} & Mon-3 & PreM-11 & PoM-7 & PreM-5 \\
\hline \multirow{5}{*}{ B } & & Mon-4 & PreM-12 & PoM-8 & PreM-6 \\
\hline & & Mon-5 & PreM-15 & PoM-9 & PreM-7 \\
\hline & & Mon-6 & PoM-2 & PoM-10 & PreM-8 \\
\hline & & Mon-7 & PoM-3 & PoM-11 & PreM-9 \\
\hline & \multirow{8}{*}{ Cluster 3} & Mon-8 & PoM-4 & PoM-14 & PreM-10 \\
\hline \multirow{7}{*}{$\mathrm{C}$} & & Mon-9 & PoM-6 & & PreM-13 \\
\hline & & Mon-10 & PoM-12 & & PreM-14 \\
\hline & & Mon-11 & PoM-13 & & \\
\hline & & Mon-12 & PoM-15 & & \\
\hline & & Mon-13 & & & \\
\hline & & Mon-14 & & & \\
\hline & & Mon-15 & & & \\
\hline
\end{tabular}


Figure 3

Hierarchical clustering of sampling sites on dendrogram in the Seti River Basin. 